\title{
Effectiveness of health literacy intervention on cardiovascular diseases among university students of Pakistan
}

\author{
Maria Nazar, Shahzad Ali Khan, Ramesh Kumar *i] and Assad Hafeez
}

\begin{abstract}
Background: Global burden of cardiovascular diseases is alarming which is intricately linked with health literacy. To what extent improvement in health literacy can lower down cardiovascular diseases occurrence has not yet properly documented. This study focused on assessing the knowledge and existing lifestyle behavior about cardiac diseases among university students. We further aimed to improve this awareness after imparting an educational intervention among undergraduate non-medical students to sensitize them about risk factors.

Method: A pre and post approaches with cross sectional study design was conducted in University of Gujrat during April-September 2017. Using structured questionnaire comprising of response items about hypertension, heart attack, stroke and preventive practices, data was randomly collected from students $(n=100)$. Survey respondents were also given a lecture regarding cardiovascular diseases awareness and a post test evaluation was also conducted on same group of students.

Results: With response rate of 86.95\%, mean age of participating students was 21.2 (SD \pm 1.34 ) years. Female students comprised of 53\% out of which 57\% were from rural background. Assessment of cardiovascular disease knowledge revealed maximum mean pre test score 30.53 (SD \pm 7.61$)$ and for post test $40.65(\mathrm{SD} \pm 4.34)(p<0.00)$. Mean score for using preventive practices was 13.02 (SD \pm 2.97 ) for pre test whereas for post test it was 14.09 (SD \pm 2.90) $(p<0.00)$. Intervention impact was significant on hypertension related complications $(p<0.000)$, symptoms of heart attack $(p<0.000)$, symptoms of stroke $(p<0.000)$ and preventive practices $(p<0.00)$.

Conclusion: Findings presented here show a fair degree of awareness among university students about study title prior to any educational intervention. However, by attending educational session, a significant increase in the positive lifestyle behavior and knowledge was noticed. We conclude that health promotion activities in educational institutes to sensitize students can bring rational changes in Pakistani society to promote healthy behavior and minimize cardiovascular disease risks.
\end{abstract}

Keywords: Health literacy, College students, University students, Cardiovascular diseases, Heart attack, Symptom and stroke

\footnotetext{
* Correspondence: drramesh1978@gmail.com

Health Services Academy, Islamabad, Pakistan
}

(C) The Author(s). 2019 Open Access This article is distributed under the terms of the Creative Commons Attribution 4.0 International License (http://creativecommons.org/licenses/by/4.0/), which permits unrestricted use, distribution, and reproduction in any medium, provided you give appropriate credit to the original author(s) and the source, provide a link to the Creative Commons license, and indicate if changes were made. The Creative Commons Public Domain Dedication waiver (http://creativecommons.org/publicdomain/zero/1.0/) applies to the data made available in this article, unless otherwise stated. 


\section{Background}

Health Literacy (HL) is the degree to which people are able to access, understand, appraise and communicate information to engage with demand of different health contexts in order to promote and maintain good health across the life course [1]. It has been repeatedly shown in different studies that health literacy in general is lower that related to the poor health outcomes in Pakistan [24]. About 17.9 million deaths reported due to cardiovascular diseases (CVD) in 2016, which contributes about $31 \%$ global mortality and major causes of death were heart attack and stroke [5]. However, the number of deaths would be increased by 23.3 million in next ten years [6]. Low and middle-income countries contribute nearly $82 \%$ in CVD related mortality due to their poor fragile health system and health illiteracy [5]. Hypertension is the major contributor of CVD and its complications are responsible for 9.4 million deaths every year [7]. Almost half of the deaths in Eastern Mediterranean Region (EMRO) occurs due to CVD results in major economic loss [8].

Pakistan reported 19\% of total mortality due to CVD $[9,10]$. Poor health literacy on prevention and control of CVD results in high mortality [3]. Hence, the health awareness and education plays a vital role in decreasing the burden of cardiovascular diseases. This would enhance the skills among patients to prevent and live better with cardiac problems and adopt their healthy lifestyles. Self-management of cardiac diseases could be learned through effective health education that improves their communication and self-confidence on management [3]. Though, this problem is prevailing in our masses but the younger population studying in colleges and universities might play a vital role by getting the proper information and strategies on management of cardiac diseases. They will play a vital role in further dissemination this information and helps in getting healthy behaviors their during early adulthood. Study recommends that the health education among youth could reverse the burden of cardiac mortality among general public [11]. To what extent awareness is needed to help people to transform their daily lifestyle practices and modifying their behavior is uncertain. Further studies are required in urban and rural areas of the country to engage people in self-management through health literacy (HL). In the context, a study was designed to assess level of CVD knowledge among non-medical students and evaluate the effectiveness of educational intervention by focusing behavioral factors that has potential to improve health literacy. We aimed to bring positive changes among young students through cost effective methods of communication and see whether increasing $\mathrm{HL}$ enables the students to become sensitive against CVD risk factors.

\section{Methods}

Study design

A cross sectional study design with pre and post intervention was conducted in 2017 by including undergraduate, non-medical students from only public university of Gujrat located in the Punjab province of Pakistan.

\section{Sampling and tool}

A proportion sample size calculation formula was used to calculate the sample size of 100 students by adopting the stratified sampling technique based on their department and academic year of study. Overall 115 students were selected randomly from the enrollment registers and all were included in pretest. However, only 100 were successful to complete this intervention hence, the response rate was (87\%). Two measurements, before and after was conducted by interviewing the students on adopted, pretested, piloted, validated tool [6, 12, 13]. Pretesting was conducted by interviewing ten university students from adjacent district.

\section{Data analysis}

Descriptive statistics was performed for sociodemographic variables were analyzed by using SPSS version 23 for frequency and percentages and knowledge level was measured in two levels; yes and no. Variables on hypertension had 12 questions with score 0-29, heart attack symptoms had 8 question with score $0-8$, stroke symptoms had 4 questions with score $0-8$, health literacy had 8 questions with score $0-53$, preventive practices variables had 8 questions scored from 5 to 22 (low to high). Frequencies with percentages were obtained for each question (pre and post) then mean scoring of pre test was compared to mean scoring of posttest of each question in each section and looked for statistical significance on paired t-test. Total mean score of each variable was obtained and compared with respective posttest mean score. In the last overall total knowledge's mean score of pre and posttest was compared for statistical significance. Preventive practices were also analyzed in the same manner and compared for statistical significance.

\section{Intervention}

Educational intervention consisted on 90 min session was given The content of session was on CVD risk factors (modifiable and non-modifiable), epidemiology of CVD, normal and high measurements of hypertension (HTN), its complications, medication, epidemiology and symptoms of heart attack, symptoms of stroke and preventive practices about knowing their usual BP, use of salt and fats intake, physical activity and its frequency, smoking habit of sample students and information 
seeking behavior. Baseline assessment was performed prior to start this intervention and end line data were collected after the intervention.

\section{Results}

Baseline data was obtained from 115 students and 100 were finally completed the end assessment with response rate of (87\%). Socio-demographic characteristics of the participants can be seen in Table 1 . The mean age of students was (21, 1.34 $\pm \mathrm{SD}$ ) years, above half (53\%) students were females out of which (57\%) were residing in rural areas. Around (58\%) fathers of the respondents were educate at least twelve years of schooling and their average income was 200-300 US \$. Media was the dominant source of information regarding CVD followed by family/friends, teachers, doctors and other sources. The intervention had a positive significant effect $(p=<0.05)$ after the training on their knowledge in different variables presented in (Table 2). Overall mean score showed significant difference between pre and post-test scores. In baseline mean score obtained was (31, SD \pm 7.6$)$ which has increased to $(41, \mathrm{SD} \pm 4.3)$ in post-test; the average change and intervention effect was 10. All the variables have improved after the intervention (Table 3).

\section{Discussion}

Health literacy is an important intervention in protecting public from chronic diseases; hence poor HL among

Table 1 Socio-demographic characteristics of the participants $(n=100)$

\begin{tabular}{lll}
\hline Variables & & Frequency (\%) \\
\hline Gender & Male & $47(47)$ \\
& Female & $53(53)$ \\
Age & $18-25$ years & $100(100)$ \\
& Mean age & 21 \\
Place they belong & Urban & $43(43)$ \\
& Rural & $57(57)$ \\
Father's Educational & Illiterate & $2(2)$ \\
Level & 12 years schooling & $58(785$ \\
& Graduation & $28(28)$ \\
& Post-graduation & $12(12)$ \\
Father's Monthly & $<200$ US \$ & $44(44)$ \\
income & $<500$ US \$ & $34(34)$ \\
& $>500$ US \$ & $22(22)$ \\
Source of information & Media & $45(45)$ \\
on CVD & Family and friends & $21(21)$ \\
& Teachers & $15(15)$ \\
& Books, news and & $14(14)$ \\
& seminars & $5(5)$ \\
\hline & Health Professional &
\end{tabular}

Table 2 Participant's Health information about cardiac diseases

\begin{tabular}{|c|c|c|c|}
\hline Variables & Pre-test (\%) & Post-test (\%) & $p$-value \\
\hline \multicolumn{4}{|l|}{ Health knowledge on Blood Pressure } \\
\hline Normal BP is $130 / 80 \mathrm{mmHg}$ & 60 & 86 & $<0.05$ \\
\hline Normal BP is $160 / 100 \mathrm{mmHg}$ & 63 & 85 & \\
\hline High BP can cause stroke & 57 & 84 & \\
\hline High BP can cause heart attack & 75 & 90 & \\
\hline $\begin{array}{l}\text { High BP can cause kidney } \\
\text { problem }\end{array}$ & 30 & 62 & \\
\hline High BP can cause eye problems & 22 & 56 & \\
\hline BP usually lasts for long time & 49 & 63 & \\
\hline Losing weight usually makes $\mathrm{BP}$ & 58 & 74 & \\
\hline Eating less salt normalize BP & 53 & 72 & \\
\hline High BP need medicine & 45 & 56 & \\
\hline Symptoms in high BP & 10 & 37 & \\
\hline High BP is dangerous & 10 & 31 & \\
\hline \multicolumn{4}{|l|}{$\begin{array}{l}\text { Information about cardiac attack } \\
\text { symptoms }\end{array}$} \\
\hline Sudden trouble & 25 & 63 & $<0.05$ \\
\hline $\begin{array}{l}\text { Symptoms are same in Male } \\
\text { and female }\end{array}$ & 59 & 82 & \\
\hline $\begin{array}{l}\text { Feeling weak, light headed } \\
\text { or faint }\end{array}$ & 21 & 58 & \\
\hline Turning gray or pale & 38 & 56 & \\
\hline $\begin{array}{l}\text { Chest pain that radiate } \\
\text { towards shoulder, jaw and } \\
\text { arm }\end{array}$ & 77 & 91 & \\
\hline $\begin{array}{l}\text { Difficulty in breathing or } \\
\text { shortness of breath }\end{array}$ & 63 & 80 & \\
\hline Stress & 10 & 60 & \\
\hline Diabetes & 57 & 83 & \\
\hline $\begin{array}{l}\text { Sudden trouble in speaking } \\
\text { and confusion }\end{array}$ & 46 & 59 & \\
\hline $\begin{array}{l}\text { Sudden dizziness, trouble } \\
\text { walking and loss of balance }\end{array}$ & 57 & 72 & \\
\hline $\begin{array}{l}\text { Sudden weakness or numbness } \\
\text { of face, arm or leg }\end{array}$ & 43 & 80 & \\
\hline $\begin{array}{l}\text { Sudden trouble seeing in one or } \\
\text { both eyes }\end{array}$ & 24 & 68 & \\
\hline \multicolumn{4}{|l|}{ Health practices related variables } \\
\hline Check your usual Blood pressure & 41 & 55 & $<0.05$ \\
\hline Add salt to your meals & 67 & 48 & \\
\hline Avoid eating fat rich food & 33 & 30 & \\
\hline Physical activity & 74 & 78 & \\
\hline Smoking & 16 & 16 & $>0.05$ \\
\hline Body weight (BMI) is appropriate & 33 & 42 & $<0.05$ \\
\hline Interested to know about CVD & 48 & 53 & \\
\hline
\end{tabular}

the community would results significant morbidity, mortality and other health complications [3]. This study has clearly shown that mortality and morbidity by CVD can 
Table 3 Positive significant change after the intervention

\begin{tabular}{llllll}
\hline Sections & Maximum score & Pre-test & Post-test & Absolute Change & $p$-Value \\
\hline Hypertension \& its complications & 29 & 17.080 & 21.38 & 4.30 & 3.68 \\
Symptoms of Heart attack & 16 & 9.280 & 12.92 & 6.000 \\
Symptoms of Stroke & 08 & 4.170 & 6.35 & 2.180 & $<0.000$ \\
Total Score (HL of CVD) & 53 & 30.53 & 40.65 & 10.12 & $<0.000$ \\
Preventive practices & 22 & 13.02 & 14.09 & 1.07 & $<0.000$ \\
\hline
\end{tabular}

be reduced by the effective awareness intervention. Varying HL levels found in our survey group manifest a large number of CVD risk factors that could treated if diagnosed earlier. Hence, this study has highlighted the value of HL awareness campaign among university students. Areas where access to health facilities is limited, the high priority to increase HL would become the only solution to promote health [3].

Findings of this study showed considerably low level of awareness about hypertension related information and symptoms of stroke that believed HL intervention is required in specific direction. Specific intervention for the raising $\mathrm{HL}$ among students showed a significant changes after posttest assessment. As we assessed from our study, the knowledge of participants raised after a simple educational intervention. A substantial improvement was observed in questions about symptoms of stroke, complications of HTN on kidneys and eyes, HTN as a silent killer and taking stress as most important cause of heart attack which further confirms that educated community such as university students or people with college education or higher can be used as targeted community groups for specific health intervention. In some studies, interventions in terms of information and training showed positive change in cardiovascular parameters in different age groups. Study supported to our findings with remarkable changes in knowledge level, attitudes and behavior of school boys regarding health physical activities which contributes heart attack prevention [14]. Several other reports have demonstrated that interactive lectures and informative session with students could bring considerable improvement in health literacy [15]. Other study launched a holistic approached intervention to improve physical activity, environment and healthy food for three years and claimed that Body Mass Index (BMI) and fitness has considerably improved among school students [16]. Pilot study on individuals with a positive family history of CVD desired results have been depicted by improved and healthy lifestyle among respondents after delivering informative lectures [17]. A positive impact of health education intervention was achieved in a study appropriate communication methods can increase the impact of $\mathrm{HE}$ and prognosis of disease.
Core abilities were developed in students and teachers about HL to empower their health [18]. A school based study revealed that a single, simple and least costly educational intervention can enhance preventive strategies among young adolescents and identified the best time to intervene have not yet started [19]. A randomized intervention study highlighted that counseling on screening and emphasis on lifestyle modifications had long lasting effects on physical activity [20].

Participants get sensitized to know their blood pressure in posttest despite the recent guidelines recommended that everyone above the age of 18 years should checked for HTN and after 20 years should be investigated for cholesterol levels as a preventive measure [21]. Pakistan Demographic Health Survey (PDHS) reported prevalence of obesity was $11 \%$ in rural men and $19 \%$ in rural women but in urban areas it was 23 and $40 \%$ in men and women respectively [22]. Recent research work showed that more reduction in dietary salt intake lowered morbidity and mortality by CVD [23].

Findings of this study have clearly indicated that students got sensitized about various CVD indicators. Across the globe, studies prove poor HL regarding CVD among populations which was subsequently improved by health interventions $[15,16,19]$. This study was a minor step to fill the knowledge gap among students, but there is a constant need to promote health literacy in every section of community to get better health outcomes. It is recommended that the university administration and academicians should include information related to cardiac health in their curriculum for to provide health literacy to their students. Time and funding constraints were the major limitation in our study.

\section{Conclusions}

The undergraduate students were initially lacking the ability to recognize the symptoms of stroke and hypertension. However, upon attending the education session, their health literacy were significantly increased..

\section{Abbreviations}

BMI: Body Mass Index; CVD: Cardiovascular diseases; EMRO: Eastern Mediterranean Region; HL: Health Literacy; HTN: Hypertension; PDHS: Pakistan Demographic Health Survey 


\section{Acknowledgements}

Authors would like to acknowledge the support provided by administration of university and Health Services Academy-Pakistan.

\section{Authors' contributions}

MN conceived the study design and developed the intervention. RK and SAK supervised the data collection and analyses. RK and SAK drafted the successive drafts of paper. AH conducted the critical review and added the intellectual content to the paper. All authors read and approved the final draft.

\section{Funding}

None.

\section{Availability of data and materials}

Most data generated during this study are included in this manuscript. Other data that may support the findings of this research are available from the corresponding author on request.

\section{Ethics approval and consent to participate}

Prior to obtain the data, students were briefed about the purpose of the study. Written informed consent was obtained and confidentiality was assured to participants about the information they provided. Study was ethically approved from the institutional review board (IRB) of Health Services Academy Islamabad Pakistan and administration permission was also sought from relevant authorities.

\section{Consent for publication}

Not applicable.

\section{Competing interests}

The authors declare that they have no competing interests.

Received: 15 February 2019 Accepted: 16 July 2019

Published online: 19 July 2019

\section{References}

1. Kawn B, Frankish J, Rootman Irv, Zumbo B, Kelly K, et al. The development of validation of measures of health literacy in different populations. University of British Columbia Institute of Health Promotion research and University of Victoria center for community health promotion research; 2006

2. Bailey SC, Fang G, Annis IE, O'Conor R, Paasche-Orlow MK, et al. Health literacy and 30-day hospital readmission after acute myocardial infarction. BMJ Open. 2015;5:e006975. https://doi.org/10.1136/bmjopen-2014-006975.

3. Kanj M, Mitic N. Promoting health and development, closing the implementation gap. 2009. https://www.who.int/healthpromotion/ conferences/7gchp/Track1_Inner.pdf.

4. Kripalani S, Goggins K, Nwosu S, Schildcrout J, Mixon AS et al. Medication non-adherence before hospitalization for acute cardiac events. J Health Commun. 2015;20(0):34-42

5. http://www.who.int/mediacentre/factsheets/fs317/en/. cited on 23-4-2018.

6. Awad A, Nafisi H. Public knowledge of cardiovascular disease and its risk factors in Kuwait: a cross sectional survey. BMC Public Health 2014;14(1131).

7. http://www.who.int/cardiovascular_diseases/publications/global_brief_ hypertension/en.

8. http://www.emro.who.int/health-topics/cardiovascular-diseases/index.html

9. Riley $\mathrm{L}$, Cowan M. WHO report, no communicable diseases country profile 2014; http://apps.who.int/iris/bitstream/10665/128038/1/9789241507509_ eng.pdf?ua=1

10. Pakistan $\mathrm{WHO}$ statistical profile. Country statistics and global health estimates by WHO and UN partners 2012. http://www.who.int/gho/en/.

11. Mackay J, Mensah GA. The atlas of heart disease and stroke. Geneva: World Health Organization \& Center for Disease Control and Prevention; 2004.

12. Li $X$, Ning N, Hao Y, Sun H, Gao L, Jiao M, et al. Health literacy in rural areas of China: hypertension knowledge survey. Int J Environ Res Public Health. 2013:10:1125-38

13. Bergman H, Reeve B, Moser R, Scholl S, Klein W. Development of a comprehensive heart disease knowledge questionnaire. Am J Health Educ. 2011;42(2):74-87.
14. Ghaffari M, Sharifirad G, Malemakan E, Hassanzadeh A. Effects of educational intervention on physical activity related knowledge, attitude and behavior of among first grade students of male high school. J Edu Health Promot. 2013:2:4

15. Smith MB, Fardy PS, Azzollini A, Magel J, Schmitz KH, Agin D. Improvement in heart health behavior and reductionin coronary artery disease risk factors in urban teenaged girls through a school based intervention: the PATH program. Am J Public Health. 2004;94:1538-43.

16. Burke RM, Meyer A, Kay C, Allensworth D, Gazmararian JA. A holistic school based intervention for improving health related knowledge, body composition and fitness in elementary school students: an evaluation of healthMPowers program. Int J Behav Nutr Phys Act. 2014;11:78.

17. Imes CC, Dougherty CM, Lewis FM, Austin MA. Outcomes of a pilot intervention study for young adults at risk for cardiovascular disease based on their family history. J Cardiovasc Nurs. 2016:31(5):433-40.

18. Chi H, Chang J, Yeh M, Chen C, Kang J, Ting H. Enhancing health literacy through developing core abilities of correct medication usage in Taiwan. J of Food and Drug Analysis. 2012;20(3):561-9.

19. Ray M, Guha S, Ray M, Kundu A, Ray B, Kundu K, et al. Cardiovascular health awareness and the effect of an educational intervention on school aged children in rural district of India. Indian Heart J. 2016;68:43-7.

20. Baumann S, Toft $U$, Aadahl $M$, Jorgensen T, Pisinger $C$. The long term effects of screening and lifestyle councelling on change in physical activity and diet:the inter99 study- a randomized controlled trial. Int J Behavior Nutrition and Phy Activity. 2015;12:33.

21. Dehmer SP, Maciosek MV LanFrance AB. Flottemesch TJ. Health benefits and cost effectiveness of asymptomatic screening for hypertension and high cholesterol and aspirin counseling for primary prevention: Ann Fam Med. 2017;15:23-36

22. Tanzil S. Jamali T. Obesity, an emerging epidemic in Pakistan- a review evidence: J Ayub Med Coll Abbottabad. 2016;28(3):597-600.

23. Wang M, Moran AE, Coxson PG, Penko J, Goldman L. Domingo KB et al. Projected impact of salt restriction on prevention of cardiovascular diseases in China: A modeling study: PLOS one. 2016;11(2):e0146820.

\section{Publisher's Note}

Springer Nature remains neutral with regard to jurisdictional claims in published maps and institutional affiliations.

Ready to submit your research? Choose BMC and benefit from:

- fast, convenient online submission

- thorough peer review by experienced researchers in your field

- rapid publication on acceptance

- support for research data, including large and complex data types

- gold Open Access which fosters wider collaboration and increased citations

- maximum visibility for your research: over $100 \mathrm{M}$ website views per year

At BMC, research is always in progress.

Learn more biomedcentral.com/submissions 